\title{
Effect of dietary lipids and other nutrients on milk odd-and branched-chain fatty acid composition in dairy ewes
}

\author{
P. G. Toral, ${ }^{1 *} \oplus$ G. Hervás, ${ }^{1} \oplus$ A. Della Badia, ${ }^{1} \oplus$ R. Gervais, ${ }^{2}$ (๑) and P. Frutos ${ }^{1} \oplus$ \\ ${ }^{1}$ Instituto de Ganadería de Montaña (CSIC-University of León), Finca Marzanas s/n, 24346 Grulleros, León, Spain \\ ${ }^{2}$ Département des Sciences Animales, Université Laval, 2425 rue de l'Agriculture, Québec G1V 0A6, Canada
}

\begin{abstract}
Milk odd- and branched-chain fatty acids (OBCFA) are largely derived from bacteria leaving the rumen, which has encouraged research on their use as biomarkers of rumen function. Targeted research has examined relationships between these fatty acids (FA) and dietary components, but interactions between the effects of lipids and other nutrients on milk OBCFA are not well characterized yet. Furthermore, factors controlling milk OBCFA in sheep are largely unknown. Thus, the present meta-analysis examined relationships between diet composition and milk OBCFA using a database compiled with lot observations from 14 trials in dairy ewes fed lipid supplements. A total of 47 lots received lipid supplements, whereas their respective controls (27 lots) were fed the same basal diets without lipid supplementation. Relationships between milk OBCFA and dietary components were first assessed through a principal component analysis (PCA) and a correlation analysis. Then, responses of milk OBCFA to variations in specific dietary components (selected on the basis of the PCA) were examined in more detail by regression analysis. According to the loading plot, dietary unsaturated $\mathrm{C} 18 \mathrm{FA}$ loaded opposite to major milk OBCFA (e.g., 15:0, 15:0 anteiso, and 17:0) and were strongly correlated with principal component 1 , which described $46 \%$ of variability. Overall, regression equations supported this negative, and generally linear, relationship between unsaturated C18 FA levels and milk OBCFA. However, the influence of C20-22 n-3 polyunsaturated FA and saturated FA was more limited. The PCA also suggested that dietary crude protein is not a determinant of milk OBCFA profile in dairy ewes, but significant relationships were observed between some OBCFA and dietary fiber or starch, consistent with a potential role of these FA as biomarkers of rumen cellulolytic and amylolytic bacteria. In this regard, regression
\end{abstract}

\footnotetext{
Received March 23, 2020.

Accepted August 6, 2020.

*Corresponding author: pablo.toral@csic.es
}

equations indicated that iso FA would show opposite responses to increasing levels of acid detergent fiber (positive linear coefficients) and starch (negative linear coefficients). Lipid supplementation would not largely affect these associations, supporting the potential of OBCFA as noninvasive markers of rumen function under different feeding conditions (i.e., with or without lipid supplementation). Because consumption of these FA may have nutritional benefits for humans, the use of high-fiber/low-starch rations might be recommended to maintain the highest possible content of milk OBCFA in dairy sheep.

Key words: anteiso fatty acid, iso fatty acid, biomarker, ruminant, sheep

\section{INTRODUCTION}

Milk odd- and branched-chain fatty acids (OBCFA) are largely derived from cell membranes of bacteria leaving the rumen (Vlaeminck et al., 2006; Bessa et al., 2009; Prado et al., 2019). Because different bacterial populations have specific enzymes responsible for de novo synthesis of membrane fatty acids (FA), variations in milk OBCFA proportions may reflect changes in the rumen bacterial community and, by extension, in rumen function (Kaneda, 1991; Vlaeminck et al., 2006; Palmer et al., 2016). This, together with the potential nutritional benefits of iso and anteiso FA consumption in humans (Shingfield et al., 2008; Ran-Ressler et al., 2014), has drawn attention to OBCFA in dairy science (Fievez et al., 2012; Palmer et al., 2016; Prado et al., 2019).

Targeted research has examined the potential of milk OBCFA as noninvasive markers to predict rumen VFA proportions, microbial protein synthesis, or susceptibility to SARA in dairy cows (Bhagwat et al., 2012; Castro-Montoya et al., 2016; Jing et al., 2018). Relationships between dietary components and milk OBCFA have also been examined, suggesting for example a positive link between the proportions of fiber in the ration and milk 15:0 iso or between dietary pectin and sugars and 15:0 anteiso (Fievez et al., 2012). Further- 
more, lipid supplementation has been reported to affect milk OBCFA profile, but their interrelationships are less well-characterized and the responsible mechanisms are not always apparent (Vlaeminck et al., 2006; Baumann et al., 2016; Vazirigohar et al., 2018).

In the studies conducted by our research team to examine the effects of supplemental lipids on milk FA profile in dairy ewes, variations in OBCFA are not always consistent (Gómez-Cortés et al., 2011; Carreño et al., 2016; Frutos et al., 2017). The reasons underlying apparent contradictory results are difficult to reconcile. It is possible that milk OBCFA responses to lipid supplements do not follow a linear model. Therefore, the range of supplementary lipid levels in our individual studies might not be broad enough to fully reflect the pattern of variation in OBCFA. Furthermore, interaction between lipids and other dietary nutrients might also exist and hinder the characterization of milk OBCFA responses to fat supplements (Gómez-Cortés et al., 2011; Vazirigohar et al., 2018). Under such conditions, a meta-analytic approach (Sauvant et al., 2008; Leduc et al., 2017; Prado et al., 2019) may lead to a better understanding of the interrelationships between supplemental lipids, other dietary components, and milk OBCFA profiles in sheep.

On this basis, this meta-analysis was conducted to gain insight into factors controlling milk OBCFA in dairy ewes. To that general aim, relationships between diet composition and milk OBCFA were examined, with particular emphasis to interactions with lipid supplementation.

\section{MATERIALS AND METHODS}

\section{Database Preparation}

A database was compiled as described by Toral et al. (2020), with information from 14 nutritional trials performed at the Instituto de Ganadería de Montaña (León, Spain) to examine the effects of lipid supplements on milk FA profile in lactating sheep (42 dietary conditions; Supplemental Table S1, https://doi.org/ 10.3168/jds.2020-18580). All of the experiments were conducted using dairy Assaf ewes with mean $( \pm$ SEM) milk yield of $2.33 \pm 0.062 \mathrm{~kg} / \mathrm{d}$, milk fat concentration of $51.8 \pm 0.76 \mathrm{~g} / \mathrm{kg}$, milk protein concentration of 49.9 $\pm 0.29 \mathrm{~g} / \mathrm{kg}$, and at $65 \pm 7.1 \mathrm{~d}$ postpartum. The assays were carried out between 2005 and 2016 under similar management conditions, in similar periods of the year (March-June) and following completely randomized designs, except in Toral et al. (2016), where a Latin square design was used. Diets consisted of TMR based on alfalfa hay (as sole forage source) and concentrates (composed of whole corn and barley grains, soybean meal, sugar beet pulp, molasses, and vitamin-mineral supplements, with different proportions), and contained no additional lipid (CON treatment) or lipid supplements that replaced other dietary ingredients on a proportionate basis (LPD treatment; Supplemental Table S1). These supplements were composed of plant oils (from sunflower seeds, soybeans, or olives), marine lipids (fish oil or marine microalgae), or combinations of both. The TMR were offered daily to ensure ad libitum intakes. Ewes had continuous access to clean drinking water and were milked in a single-side milking parlor with 10 stalls (DeLaval, Madrid, Spain).

Individual milk FA profiles were not available in some experiments that included the lot of animals as the experimental unit. Therefore, for the sake of homogeneity, arithmetic means were calculated for each dietary condition in experiments where ewes were housed in individual pens and lot means were entered in the database for all the trials. To obtain one final observation per lot of animals, arithmetic means were also calculated if repeated measures had been conducted, using only the results obtained after 3 or more weeks of adaptation to the experimental treatments to ensure steady-state responses. The number of lot observations entered in the database and their classification by trial and experimental treatment (i.e., CON or LPD) are reported in Supplemental Table S1.

Diets were analyzed for chemical composition using standard methods (e.g., Frutos et al., 2017), with the exception of some missing starch concentrations that were estimated using the INRA (2007) tables of feed composition. Milk OBCFA proportions were determined using similar base-catalyzed methylation techniques and chromatographic equipment and conditions (e.g., Hervás et al., 2008; Frutos et al., 2017). The results of 17:0 iso and 17:0 anteiso were excluded from the database because of the detection of coelutions with minor 16:1 isomers that could be affected by lipid supplementation (Gómez-Cortés et al., 2008; Hervás et al., 2008). This is particularly observed when sheep are fed fish oil, which is a source of cis-9 16:1 (e.g., Toral et al., 2016).

\section{Statistical Analysis}

Relationships between dietary components and milk OBFCA proportions (i.e., 13:0, iso 13:0, anteiso 13:0, iso $14: 0,15: 0$, iso $15: 0$, anteiso $15: 0$, iso $16: 0,17: 0$, cis- 9 $17: 1$, and iso 18:0) were first assessed through a principal component analysis (PCA) using the R-project 
software (http://www.r-project.org, version 3.2.3). The CORR procedure of the SAS software package (version 9.4, SAS Institute Inc., Cary, NC) was used to generate Pearson correlation coefficients $(r)$ among variables. On the basis of the PCA and correlation results, relationships between selected nutrients [i.e., ADF, total starch, and unsaturated C18 FA (UFA18) concentrations] and milk OBCFA were then examined using the MIXED procedure of SAS. The observations in the database were the lot means, as detailed in the previous section. For each milk OBCFA, the candidate prediction models included the fixed effects of the experimental treatment (CON vs. LPD), the linear and quadratic effects of the selected dietary nutrient, and the interactions between them. The trial was designated as the random effect in the model, and observations were weighed by the inverse of the squares of their standard errors (St-Pierre, 2001; Sauvant et al., 2008). The prediction model was as follows (for simplicity, it is written without weighing the observations):

$$
\begin{aligned}
y_{i j k}=(a+ & \left.a_{j}\right)+\left(b+b_{j}\right) \times x_{i j}+\left(c+c_{j}\right) \\
& \times x_{i j}^{2}+s_{l}+\varepsilon_{i j k},
\end{aligned}
$$

where $y_{i j k}$ is the estimated performance trait for the $i$ th lot of treatment $j\left(j=\mathrm{CON}\right.$ or LPD), $x_{i j}$ is the level of the selected dietary component for the $i$ th lot of treatment $j, a$ is the overall intercept, $a_{j}$ is the specific intercept for treatment $j, b$ and $c$ are the overall regression coefficients (linear and quadratic, respectively), $b_{j}$ and $c_{j}$ are the specific regression coefficients for treatment $j$ (linear and quadratic, respectively), $s_{l}$ is the random effect of the lth study, and $\varepsilon_{i j k}$ is the residual error. In the model, the weights would appear as multiplicative factors of the diagonal elements of the error variancecovariance matrix (Draper and Smith, 1998; Sauvant et al., 2008).

The corrected Akaike information criterion was used to select prediction models among those that were found to be significant. The linear and quadratic effects of the particular nutrient, and the interactions between each of them and the effect of the experimental treatment were only kept in the final selected model when significant (i.e., when $P<0.05$ ). Outliers, defined as data for which the absolute value of conditional studentized residuals was $\geq 3.0$, represented $8.8 \%$ of initial observations and were excluded from the database. Predictions models were initially evaluated in terms of collinearity (variance inflation factor) and homoscedasticity by the normality of the residuals, using the REG procedure of SAS. Then, prediction bias was assessed by regressing residuals against predicted values, which were centered around their mean value and used as an independent variable (St-Pierre, 2003). The intercept, at the mean value of the regressor, was used to assess overall model bias, whereas the slope was used to determine the linear bias. Respective $t$-tests were conducted to confirm if the slopes and the intercepts were not significantly different from zero (Mitchell, 1997). The root mean squared prediction error, estimated from the difference between observed and model predicted values, was used to further evaluate models. Decomposition of mean squared prediction error into error due to overall prediction bias, error due to linear bias, and error due to random variation was performed according to Bibby and Toutenburg (1977).

Tables 2 to 4 report the least squares means $( \pm \mathrm{SEM})$ of prediction model parameter estimates (intercepts and linear or quadratic regression coefficients). These were calculated separately for CON and LPD treatments when the effect of the experimental treatment (for intercepts) or interactions (for intercepts and linear or quadratic coefficients) were significant. On the contrary, when the interactions were not significant, prediction model parameter estimates were calculated for CON and LPD together, which resulted in a single mean $( \pm \mathrm{SEM})$ for the 2 experimental treatments. Because the effects of dietary UFA level and experimental treatments (addition or not of lipids to the diet) could be confounded, the effect of the experimental treatment and the respective interactions were removed from the prediction model when the effect of diet UFA level was studied.

\section{RESULTS}

As shown in Table 1, diets offered to ewes were characterized by high concentrate levels, with low variations in $\mathrm{CP}$ compared with those observed in fiber or starch contents. By design, the LPD treatment was rich in total FA and UFA18, and no C20-22 n-3 PUFA were ever detected in the CON. In both treatments, the most abundant milk OBCFA was 15:0, followed by other 15-, 16-, and 17-carbon FA, whereas branched-chain C13 FA were the least abundant.

The PCA discriminated 2 principal components (PC) that described 46.0 (PC1) and $21.4 \%$ (PC2) of the variation in diet composition and milk OBCFA, as well as a PC3 that accounted for $9.6 \%$ of variability. The score plot (Supplemental Figure S1, https://doi.org/10 $.3168 /$ jds.2020-18580) showed that the PC1 tended to separate 2 major groups based on lipid supplementation; lots of ewes in the CON were largely in the positive range, whereas those from the LPD treatment were 
Table 1. Diet composition, milk yield, milk fat concentration, and milk odd- and branched-chain fatty acid (OBCFA) proportions in dairy ewes fed diets with no supplementation (CON) or supplemented with lipids (LPD)

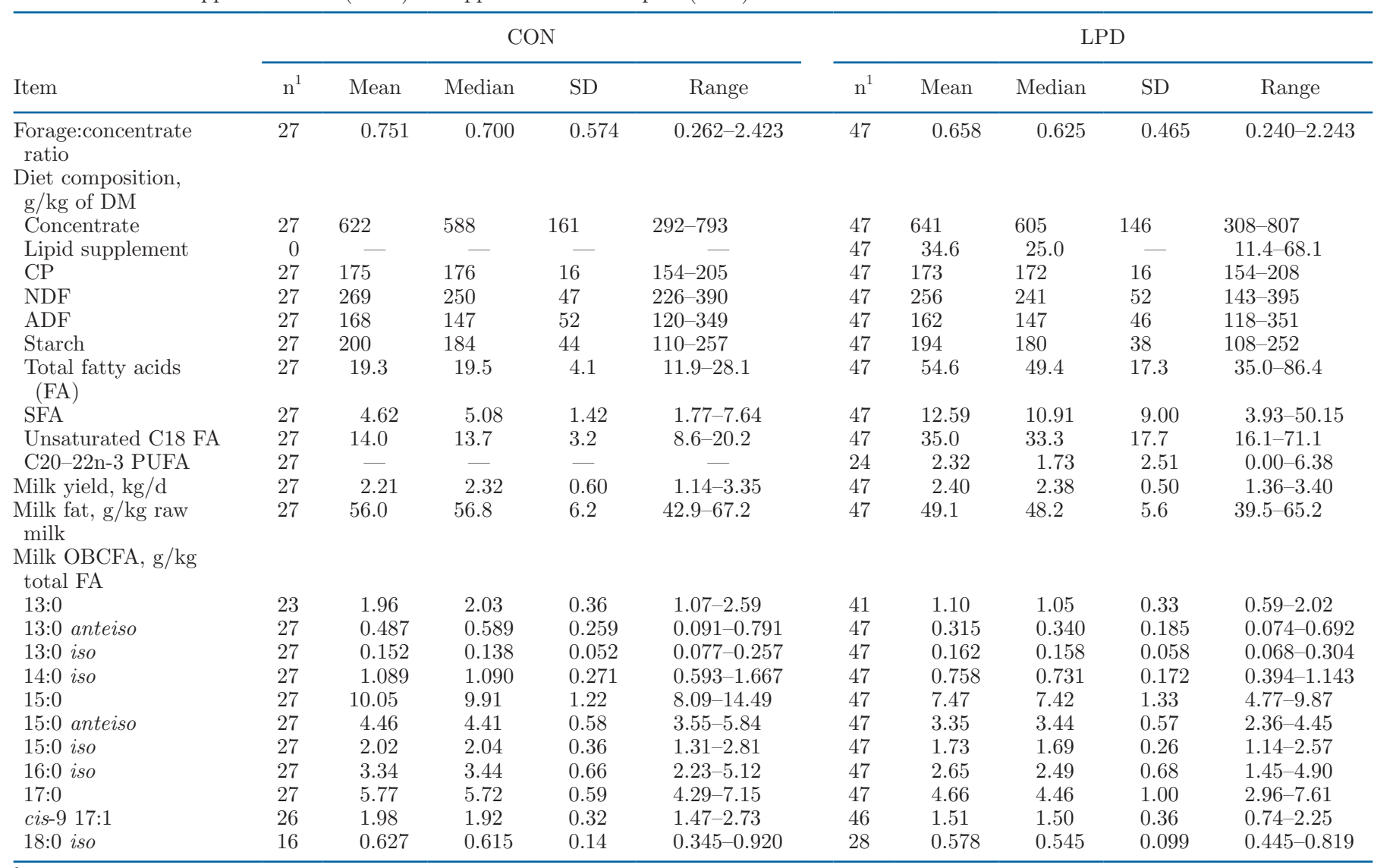

${ }^{1}$ Number of lot observations (see Supplemental Table S1, https://doi.org/10.3168/jds.2020-18580, for further details).

often in the negative range. No clear discrimination of lots was observed based on PC2 or PC3. The loading plot (Figure 1) showed that proportions of milk 15:0, 15:0 anteiso, 14:0 iso, cis-9 17:1, and 17:0 loaded opposite to dietary UFA18 and total FA, and both groups of variables were clearly correlated with $\mathrm{PC} 1$, with no evident relationship with $\mathrm{PC} 2$. However, milk 13:0 anteiso was only correlated, positively, with $\mathrm{PC} 2$, which also showed a certain relationship although less clear with other dietary components, such as C20-22 n-3 PUFA (negative) or starch (positive). In this regard, dietary starch loaded opposite to milk 13:0 iso and 15:0 iso and to $\mathrm{ADF}$ and forage:concentrate ratio, whereas $\mathrm{CP}$ positioned close to the origin of the plot, with no relationship with any of the main PC. Similarly, correlation analysis showed that OBCFA were not associated with CP ( $P>0.10$; Supplemental Table S2, https://doi.org/ 10.3168/jds.2020-18580), whereas opposite correlations were detected with fiber (e.g., $r=0.54$ and 0.62 for the relationships between $\mathrm{ADF}$ and 13:0 iso and 15:0 iso, respectively; $P<0.001$ ) and starch (e.g., $r=-0.62$ and -0.56 for the relationships with 13:0 iso and 15:0 iso, respectively; $P<0.001)$. Dietary UFA18 and total FA were negatively correlated with milk OBCFA (e.g., $r=$ -0.85 and -0.82 for their respective relationships with 15:0; $P<0.001$ ), but weaker or nonsignificant correlations were detected between OBCFA and dietary SFA or C20-22n-3 PUFA.

On this basis, relationships between milk OBCFA proportions and dietary UFA18, starch and ADF concentrations were examined by regression analysis, and parameter estimates from best fit models are reported in Tables 2, 3, and 4, respectively. Although total FA in the diet showed a strong correlation with milk OBCFA in the PCA, its closeness to UFA18 in the loading plot would suggest that the latter FA (present in both vegetable and marine lipids) were the major determinant of dietary FA effects, whereas C20-22n-3 PUFA (exclusive from marine lipids) would have a weaker effect. Therefore, total FA were not included in the regression analysis to avoid redundancy, and observations from lots of ewes fed plant oils, marine lipids, or combinations of both supplements were grouped in the LPD treatment. 


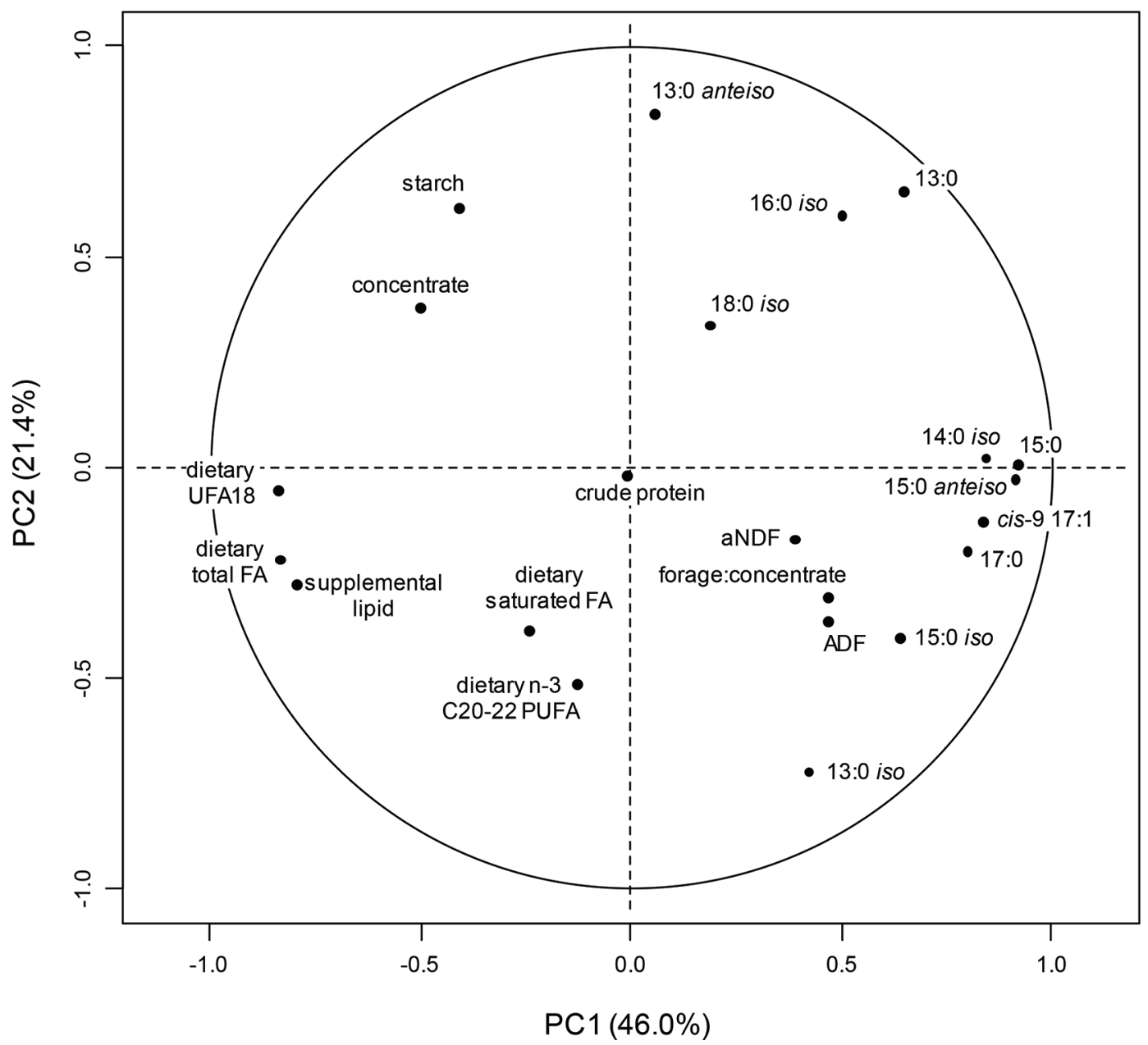

Figure 1. Principal component analysis of dietary composition and milk odd- and branched-chain fatty acids in dairy ewes fed diets with no supplementation or supplemented with lipids. Loading plot projected on the basis of the 2 major principal components (PC1 and PC2). $\mathrm{FA}=$ fatty acids; UFA18 = dietary unsaturated C18 fatty acids; aNDF $=$ NDF assayed with a heat-stable amylase and expressed inclusive of residual ash.

Prediction models for the relationships between 18:0 iso and UFA18 or starch, which were not significant, are not shown in tables. Fit statistics (Supplemental Tables S3, S4, and S5, https://doi.org/10.3168/jds .2020-18580) indicated absence of overall prediction bias for all the selected models (i.e., the intercepts of the plots of the residual vs. predicted values were not different from zero; $P>0.10)$. However, linear biases (i.e., the slopes of the plots were significantly or tended to be significantly different from zero) put into question the accuracy of some prediction models, such as those describing relationships between dietary UFA18 and 17:0 or cis-9 17:1, between ADF and 15:0 or cis-9 17:1, and between starch and 13:0, 15:0, 17:0, or cis-9 17:1.

Linear effects of nutrients were generally significant (Tables 2, 3, and 4). On the contrary, the $P$-values for their quadratic effects and the interactions between experimental treatment and dietary components were rarely below 0.05. A significant effect of the experimental treatment was found in most cases $(P<0.05)$, and therefore, intercepts in the prediction models were calculated separately for CON and LPD treatments.

Supplemental Figures S2, S3, and S4 (https://doi .org/10.3168/jds.2020-18580) report the observations and graphical representations of regression equations to provide information on the different dispersion of data in each experimental treatment, and to try to help explaining equations. Overall, negative linear or quadratic relationships were usually found between milk OBCFA and UFA18 in the diet $(P<0.05$, Table 2 and Supplemental Figure S2).

Dietary ADF and starch levels showed consistently opposite relationships with most milk iso FA. Thus, 13:0 iso, 14:0 iso, and 15:0 iso proportions were posi- 
Table 2. Prediction model parameter estimates (mean \pm SE) of milk odd- and branched-chain fatty acid (OBCFA) proportions in relation to dietary unsaturated C18 fatty acid concentration (UFA18) in dairy ewes ${ }^{1}$

\begin{tabular}{|c|c|c|c|c|c|}
\hline $\begin{array}{l}\text { OBCFA, } \mathrm{g} / \mathrm{kg} \text { of total } \\
\text { fatty acids in milk }\end{array}$ & Intercept & $\begin{array}{l}\text { Linear UFA18 } \\
\text { coefficient }^{2}\end{array}$ & $\begin{array}{l}\text { Quadratic UFA18 } \\
\text { coefficient }^{3}\end{array}$ & \multicolumn{2}{|c|}{$P$-value ${ }^{4}$} \\
\hline $13: 0$ & $2.226 \pm 0.141$ & $-0.0288 \pm 0.0019$ & 0 & $<0.001$ & - \\
\hline $13: 0$ iso & $0.186 \pm 0.015$ & $-0.00119 \pm 0.00051$ & $14 \mathrm{E}^{-06} \pm 6.1 \mathrm{E}^{-06}$ & 0.024 & 0.025 \\
\hline 14:0 iso & $1.055 \pm 0.061$ & $-0.00799 \pm 0.00135$ & 0 & $<0.001$ & - \\
\hline $15: 0$ & $10.850 \pm 0.258$ & $-0.0916 \pm 0.0079$ & 0 & $<0.001$ & - \\
\hline 16:0 iso & $3.870 \pm 0.190$ & $-0.0641 \pm 0.0078$ & $0.000597 \pm 0.000122$ & $<0.001$ & $<0.001$ \\
\hline $17: 0^{5}$ & $6.523 \pm 0.171$ & $-0.0501 \pm 0.0039$ & 0 & $<0.001$ & - \\
\hline cis-9 $17: 1^{5}$ & $2.469 \pm 0.084$ & $-0.0262 \pm 0.0027$ & 0 & $<0.001$ & - \\
\hline
\end{tabular}

${ }^{1}$ Parameter estimates correspond to prediction models that were selected among all candidate significant models based on the corrected Akaike information criterion. Fit statistics are reported in Supplemental Table S3 (https://doi.org/10.3168/jds.2020-18580).

${ }^{2}$ Zero values indicate nonsignificant linear effects of dietary unsaturated C18 fatty acid (UFA18 $\mathrm{L}_{\mathrm{L}}$ ) concentration $(\mathrm{g} / \mathrm{kg}$ of diet DM).

${ }^{3}$ Zero values indicate nonsignificant quadratic effects of dietary unsaturated C18 fatty acid (UFA18 $)$ concentration (g/kg of diet DM).

${ }^{4}$ Significance of linear effect of dietary unsaturated C18 fatty acid concentration (UFA18 ${ }_{\mathrm{L}}$ ) and quadratic effect of dietary unsaturated C18 fatty acid concentration $\left(\mathrm{UFA} 18_{\mathrm{Q}}\right)$.

${ }^{5}$ Regression of residuals against predicted values indicate a trend or a significant linear bias in the model $(P=0.074,0.012$, and $<0.001$ for $13: 0$ anteiso, 17:0, and cis-9 17:1, respectively; Supplemental Table S3, https://doi.org/10.3168/jds.2020-18580).

tively related to $\mathrm{ADF}$ content $(P<0.05$; Table 3 and Supplemental Figure S3) and negatively to starch $(P$ $<0.05$; Table 4 and Supplemental Figure S4). Positive relationships were also detected between $\mathrm{ADF}$ and 17:0 $(P<0.001)$, and between starch and 13:0 anteiso $(P$ $<0.001)$.

\section{DISCUSSION}

The relationship between milk OBCFA and dietary composition was examined in this study to try to advance our understanding of interactions with lipid supplementation and provide information on factors con-

Table 3. Prediction model parameter estimates (mean $\pm \mathrm{SE}$ ) of milk odd- and branched-chain fatty acid (OBCFA) proportions in relation to dietary acid detergent fiber concentration (ADF) in dairy ewes fed diets with no supplementation (CON) or supplemented with lipids (LPD) ${ }^{1}$

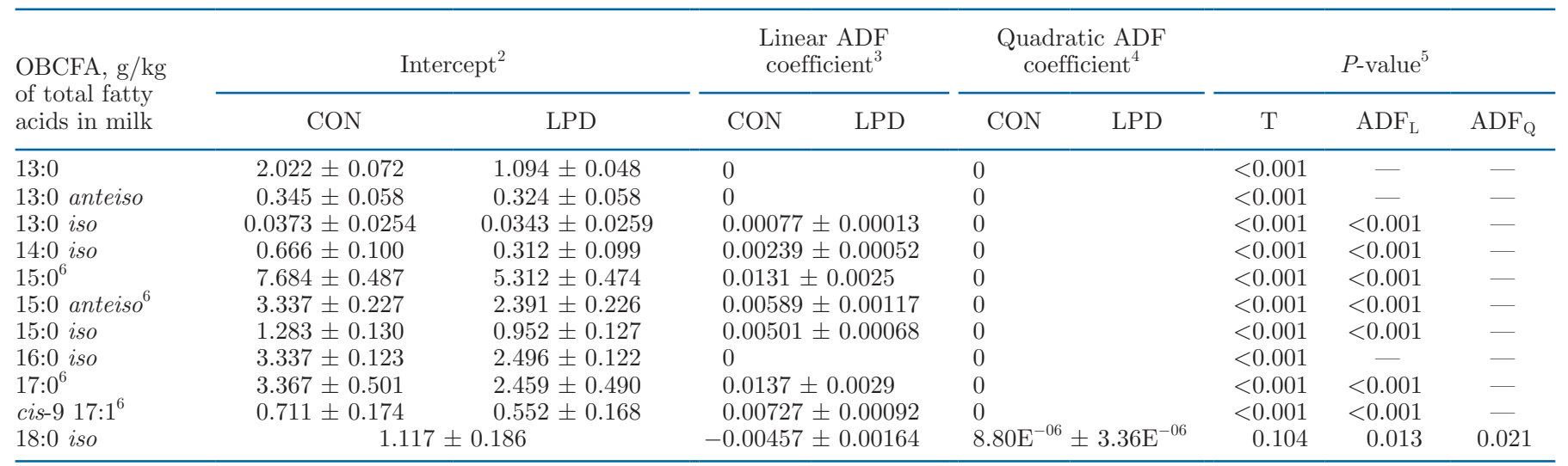

${ }^{1}$ Parameter estimates correspond to prediction models that were selected among all candidate significant models based on the corrected Akaike information criterion. Fit statistics are reported in Supplemental Table S4 (https://doi.org/10.3168/jds.2020-18580).

${ }^{2}$ Common intercept values for CON and LPD indicate nonsignificant effects of experimental treatment $(\mathrm{T})$.

${ }^{3}$ Common coefficient values for CON and LPD indicate a significant $(P<0.05)$ linear effect of dietary acid detergent fiber $\left(\mathrm{ADF}_{\mathrm{L}}\right) \mathrm{concentration}$ $(\mathrm{g} / \mathrm{kg}$ of diet $\mathrm{DM})$ in the absence of a significant $\mathrm{T} \times \mathrm{ADF}_{\mathrm{L}}$ interaction. Zero values indicate nonsignificant effects of $\mathrm{ADF}_{\mathrm{L}}$ and $\mathrm{T} \times \mathrm{ADF}_{\mathrm{L}}$.

${ }^{4}$ Common coefficient values for $\mathrm{CON}$ and LPD indicate a significant $(P<0.05)$ quadratic effect of dietary acid detergent fiber $\left(\mathrm{ADF}_{\mathrm{Q}}\right) \mathrm{concen}$ tration $(\mathrm{g} / \mathrm{kg}$ diet $\mathrm{DM})$ in the absence of a significant $\mathrm{T} \times \mathrm{ADF}_{\mathrm{Q}}$ interaction. Zero values indicate nonsignificant effects of $\mathrm{ADF}_{\mathrm{Q}}$ and $\mathrm{T} \times \mathrm{ADF}_{\mathrm{Q}}$. ${ }^{5}$ Significance of experimental treatment effect $(\mathrm{T})$, linear effect of dietary ADF concentration $\left(\mathrm{ADF}_{\mathrm{L}}\right)$, and quadratic effect of dietary ADF concentration $\left(\mathrm{ADF}_{\mathrm{Q}}\right)$. The interactions of $\mathrm{T} \times \mathrm{ADF}_{\mathrm{L}}$ and $\mathrm{T} \times \mathrm{ADF}_{\mathrm{Q}}$, nonsignificant for all variables, were excluded from the models.

${ }^{6}$ Regression of residuals against predicted values indicate a trend or a significant linear bias in the model $(P=0.026,0.076,0.002$, and 0.088 for 15:0, 15:0 anteiso, 17:0, and cis-9 17:1, respectively; Supplemental Table S4, https://doi.org/10.3168/jds.2020-18580). 
trolling milk OBCFA in sheep, 2 issues that remained largely unknown (Vlaeminck et al., 2006; Baumann et al., 2016; Vazirigohar et al., 2018).

Results from the loading plot of the PCA (Figure 1) supported relevant relationships between diet composition and milk OBCFA in ewes. The strongest influence would be that of dietary lipid level, based on the position of UFA18 and total FA relative to PC1, which explained most of the variability in the database, whereas a different (and weaker) effect of dietary C20-22 n-3 PUFA and SFA would be extrapolated from their position in the loading plot. A certain contrast between the effects of different FA on milk OBCFA was previously indicated in dairy cows (Vlaeminck et al., 2006), with relatively consistent decreases after plant oil supplementation (rich in UFA18; Collomb et al., 2004; Rego et al., 2005; Saliba et al., 2014) and less clear responses when receiving marine lipids (rich in 20:5n-3 and 22:6n3; Shingfield et al., 2003; Boeckaert et al., 2008; Fougère et al., 2018). Similarly, in the studies included in our database, plant lipids usually promoted decreases or no variation in the concentration of these FA in milk (e.g., Gómez-Cortés et al., 2008; Hervás et al., 2008), whereas fish oil caused reductions, no changes, or even increases in the content of certain OBCFA, such as 17:0 and 18:0 iso (Carreño et al., 2016; Toral et al., 2016; Frutos et al., 2017).

The mechanisms that may explain the negative effect of supplementary UFA18 on milk OBCFA were listed by Baumann et al. (2016). The first mechanism seems to be linked to the toxic effect of unsaturated lipids on microbial growth (Lourenço et al., 2010; Enjalbert et al., 2017), which would decrease bacterial abundance and, therefore, the rumen outflow of FA of microbial origin. This toxicity would particularly affect cellulolytic bacteria (Maia et al., 2007; Enjalbert et al., 2017), although its extent in our conditions might have been limited, because neither the performance nor the ruminal fermentation of ewes fed supplemental UFA18 were impaired at our levels of inclusion (up to $6 \%$ diet DM, see Table 1; Gómez-Cortés et al., 2008; Hervás et al., 2008). This hypothesis of a minor relevance of the first mechanism in explaining our results would be reflected in the weak effect of increasing levels of UFA18 on iso 15:0 (Table 2 and Supplemental Figure S2, https://doi .org/10.3168/jds.2020-18580), which seems to be particularly abundant in cellulolytic bacteria (Vlaeminck et al., 2006).

A second mechanism that may account for the inverse relationship between UFA18 and milk OBCFA would be related to changes in the function rather than in the abundance of ruminal bacteria. Specifically, an increased availability of preformed FA for microbial uptake in the rumen has been shown to cause a reduction in de novo FA synthesis by bacteria (Emmanuel, 1978; Weisbjerg et al., 1992).

Third, mammary mechanisms could also be involved, because a significant proportion of linear odd-chain FA

Table 4. Prediction model parameter estimates (mean \pm SE) of milk odd- and branched-chain fatty acid (OBCFA) proportions in relation to dietary starch concentration in dairy ewes fed diets with no supplementation (CON) or supplemented with lipids (LPD) ${ }^{1}$

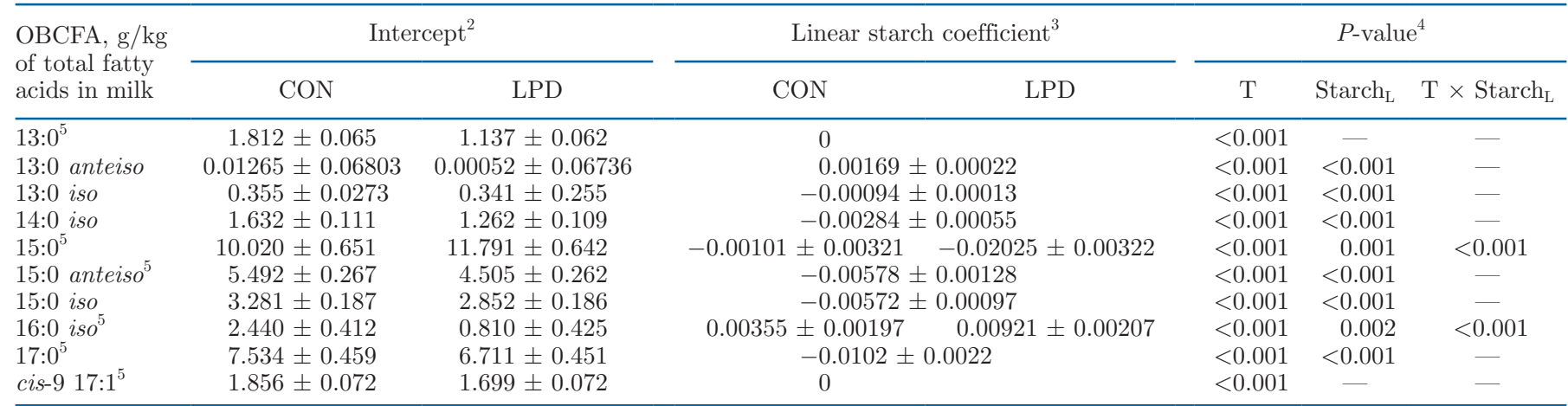

${ }^{1}$ Parameter estimates correspond to prediction models that were selected among all candidate significant models based on the corrected Akaike information criterion. Fit statistics are reported in Supplemental Table S5 (https://doi.org/10.3168/jds.2020-18580).

${ }^{2}$ Common intercept values for CON and LPD indicate nonsignificant effects of experimental treatment $(\mathrm{T})$.

${ }^{3}$ Common coefficient values for CON and LPD indicate a significant $(P<0.05)$ linear effect of dietary starch $\left(\mathrm{Starch}_{\mathrm{L}}\right)$ concentration $(\mathrm{g} / \mathrm{kg}$ of diet $\mathrm{DM}$ ) in the absence of a significant $\mathrm{T} \times \mathrm{Starch}_{\mathrm{L}}$ interaction. Zero values indicate nonsignificant effects of $\mathrm{Starch}_{\mathrm{L}}$ and $\mathrm{T} \times \mathrm{Starch}_{\mathrm{L}}$.

${ }^{4}$ Significance of experimental treatment effect $(\mathrm{T})$, linear effect of dietary starch concentration $\left(\mathrm{Starch}_{\mathrm{L}}\right)$, and interaction of $\mathrm{T} \times \mathrm{Starch}_{\mathrm{L}}$. The quadratic effect of dietary starch concentration $\left(\mathrm{Starch}_{\mathrm{Q}}\right)$ and the interaction $\mathrm{T} \times \mathrm{Starch}_{\mathrm{Q}}$, nonsignificant for all variables, were excluded from the models.

${ }^{5}$ Regression of residuals against predicted values indicate a trend or a significant linear bias in the model $(P=0.012,0.046,0.076,0.092,0.001$, and 0.032 for 13:0, 15:0, 15:0 anteiso, 16:0 iso, 17:0, and cis-9 17:1, respectively; Supplemental Table S5, https://doi.org/10.3168/jds.2020 $-18580)$. 
is synthesized endogenously in the mammary gland using propionate as the precursor for the fatty acyl chain (Fievez et al., 2012; Vlaeminck et al., 2015). On the contrary, branched-chain FA do not seem to be de novo synthesized in the mammary tissue of ruminants (Vlaeminck et al., 2006, 2015). Thus, the general inhibition of mammary de novo FA synthesis by unsaturated 18-carbon FA (Rego et al., 2005; Mele et al., 2008; Saliba et al., 2014) could have contributed to decrease the relative abundance of linear odd-chain FA in milk, in particular 13:0 and 15:0.

Furthermore, it could be speculated about a putative dilution of OBCFA in plasma lipids in the LPD treatment due to an increase in the duodenal absorption of other preformed FA, which would result in potential changes in the profile of available FA for mammary uptake. Yet, we are not aware of published studies comparing the transfer efficiency of different preformed FA from plasma into milk in dairy ewes. Targeted research using isotopic tracers would be advisable to provide conclusive evidence in this regard.

In addition to lipids, dietary ADF and starch levels would also be related to changes in the OBCFA profile of ewe milk (Supplemental Figures S3 and S4, https: //doi.org/10.3168/jds.2020-18580). These putative relationships will be discussed first, and interactions with the presence of supplemental lipids in the diet thereafter.

Previous studies have suggested a positive association between dietary fiber and certain milk OBCFA in dairy cows and goats, which would be accounted for by the specific FA composition of membrane lipids in cellulolytic bacteria (Bas et al., 2003; Patel et al., 2013; Vazirigohar et al., 2018). For example, some fiberdegrading species, such as Ruminococcus albus, Ruminococcus flavefaciens, and Butyrivibrio fibrisolvens, show high proportions of iso FA (Vlaeminck et al., 2006). Furthermore, 15:0 iso is particularly abundant in solid-associated bacteria, which are rich in cellulolytic populations (Vlaeminck et al., 2006; Fievez et al., 2012). In line with this, dietary ADF loaded closely to milk 15:0 iso in the PCA (see Figure 1) and was also positively related to 13:0 iso, 14:0 iso, and 15:0 iso (see Supplemental Figure S3, https://doi.org/10.3168/ jds.2020-18580). Interspecies variations in ruminal OBCFA profile have been reported in a direct comparison between ovine and bovine (Toral et al., 2018), likely as a result from differences in their rumen microbial community (Moon et al., 2010; Lee et al., 2012). However, our results would support a similar role of milk iso FA as biomarkers of dietary fiber concentration, and hence of rumen cellulolytic bacteria abundance, in sheep and other ruminant species (Vlaeminck et al., 2006;
Fievez et al., 2012). However, the relationship between ADF levels and 16:0 iso (nonsignificant) and 18:0 iso (negative linear effect) would prevent from generalizing about a similar behavior for all iso FA in dairy ewes. Thus, in the ovine species, the 2 latter iso FA might be less adequate biomarkers of dietary fiber proportion than, for example, 15:0 iso.

Rumen amylolytic bacterial populations, such as Ruminobacter amylophilus, Selenomonas ruminantium, Streptococcus bovis, and Succinimonas amylolytica, have low concentrations of iso branched-chain FA (Fievez et al., 2012), consistent with the inverse relationship between starch and milk 13:0 iso, 14:0 iso, or 15:0 iso in our animals (Supplemental Figure S4, https://doi .org/10.3168/jds.2020-18580). An increase in linear odd-chain and anteiso FA proportions with increments in the abundance of amylolytic bacteria would also be expected (Vlaeminck et al., 2006), in agreement with responses in 13:0 anteiso to varying starch levels, which might support a role of this FA as biomarkers of amylolytic bacteria in sheep. On the contrary, prediction biases were found for 15:0 anteiso and linear odd-chain FA, which would question the apparent negative relationship between these milk FA and dietary starch in our conditions (Supplemental Table S5, https://doi .org/10.3168/jds.2020-18580). In any event, high milk proportions of $\mathrm{C} 15$ and $\mathrm{C} 17$ odd-chain and anteiso FA have been suggested as biomarkers of ruminal acidosis (Fievez et al., 2012), but signs of this pathological condition were not evident in our sheep.

Overall, variations in milk OBCFA, and particularly in 13:0 iso, 14:0 iso, and 15:0 iso, with increasing dietary ADF or starch levels appeared to be hardly affected by the presence of supplemental lipids, which is in line with previous results in dairy ewes fed diets with different forage:concentrate ratios and supplemented or not with sunflower oil (Gómez-Cortés et al., 2011). Similarly, interactions between the effects of forage:concentrate ratio and plant oils on milk OBCFA appear to be rare in dairy cows (Saliba et al., 2014; Ventto et al., 2017). These results suggest putative independent effects of these dietary components (supplemental lipids, and fiber or starch) on the rumen bacterial community and would support the potential of milk OBCFA as biomarkers of rumen function under different feeding conditions (i.e., with or without lipid supplementation). In addition, given the potential benefits of branched-chain FA consumption for humans (Shingfield et al., 2008; Ran-Ressler et al., 2014) and the reductions in their milk concentration after lipid supplementation (Hervás et al., 2008; Frutos et al., 2017), the use of high-fiber/ low-starch rations might be recommended to maintain the highest possible milk contents of these FA in dairy 
sheep fed lipid supplements. Feeding high-forage diets would also be beneficial to obtain milk with greater 18:3n-3 concentrations and minimize the incidence of the shift from trans-11 to trans-10 FA (Mele et al., 2008; Shingfield et al., 2008; Ventto et al., 2017).

Finally, relationships between dietary $\mathrm{CP}$ and milk OBCFA have been reported in dairy cows. In particular, 17:0 has been suggested as a specific biomarker of protein deficiency, although negative correlations between $\mathrm{CP}$ and 17:0 iso and 17:0 anteiso have also been found (Cabrita et al., 2003; Prado et al., 2019). As previously explained, we removed 17:0 iso and 17:0 anteiso from our database because of some coelutions with minor 16:1 isomers, and observed no relationship between diet CP and other milk OBCFA. This lack of apparent relationships and so the discrepancy with the studies mentioned above could probably be due to the high $\mathrm{CP}$ content in our diets and its little variation compared with other nutrients, such as fiber, starch, or lipids.

\section{CONCLUSIONS}

Our results support that, in dairy ewes, milk OBCFA are strongly related to dietary lipids, and moderately related to other dietary components. Unsaturated C18 FA levels, which are negatively correlated with milk OBCFA, appear to explain the largest proportion of the variability, whereas the influence of $\mathrm{C} 20-22 \mathrm{n}-3$ PUFA and SFA would be more limited. Both ruminal and mammary mechanisms may account for the inverse relationship between unsaturated FA and OBCFA. Dietary $\mathrm{CP}$ does not seem to be a determinant of milk OBCFA profile in dairy ewes. However, significant relationships exist between some OBCFA and dietary fiber or starch, consistent with a potential role of these FA as biomarkers of rumen cellulolytic and amylolytic bacteria. Specifically, iso FA show opposite responses to increasing ADF (positive) and starch levels (negative). Lipid supplementation would not largely affect these associations, supporting the potential of OBCFA as noninvasive markers of rumen function under different feeding conditions (i.e., with or without lipid supplementation). Because consumption of these FA may have nutritional benefits for humans, the use of high-fiber/low-starch rations would be recommended to maintain the highest possible content of milk OBCFA in dairy sheep.

\section{ACKNOWLEDGMENTS}

This work was supported by the Spanish Research State Agency (Agencia Estatal de Investigación) and the European Regional Development Fund (project AGL2017-87812-R, AEI/FEDER, UE). P. G. Toral benefited from a Ramón y Cajal research contract (RYC-2015-17230) and A. Della Badia from a FPI predoctoral contract (PRE2018-086174), from the Spanish Ministries of Economy and Competitiveness (MINECO) and Science and Innovation (MICINN), respectively. Co-funding by the European Social Fund is also acknowledged. The authors thank M.-P. Létourneau-Montminy (Université Laval, Québec, Canada) for helpful assistance with statistical analysis. The authors have not stated any conflicts of interest.

\section{REFERENCES}

Bas, P., H. Archimède, A. Rouzeau, and D. Sauvant. 2003. Fatty acid composition of mixed-rumen bacteria: Effect of concentration and type of forage. J. Dairy Sci. 86:2940-2948. https://doi.org/10 .3168/jds.S0022-0302(03)73891-0.

Baumann, E., P. Y. Chouinard, Y. Lebeuf, D. E. Rico, and R. Gervais. 2016. Effect of lipid supplementation on milk odd- and branchedchain fatty acids in dairy cows. J. Dairy Sci. 99:6311-6323. https: //doi.org/10.3168/jds.2015-10746.

Bessa, R. J. B., M. R. G. Maia, E. Jerónimo, A. T. Belo, A. R. J Cabrita, R. J. Dewhurst, and A. J. M. Fonseca. 2009. Using microbial fatty acids to improve understanding of the contribution of solid associated bacteria to microbial mass in the rumen. Anim. Feed Sci. Technol. 150:197-206. https://doi.org/10.1016/j .anifeedsci.2008.09.005.

Bhagwat, A. M., B. De Baets, A. Steen, B. Vlaeminck, and V. Fievez. 2012. Prediction of ruminal volatile fatty acid proportions of lactating dairy cows based on milk odd- and branched-chain fatty acid profiles: New models, better predictions. J. Dairy Sci. 95:3926-3937. https://doi.org/10.3168/jds.2011-4850.

Bibby, J., and H. Toutenburg. 1977. Prediction and Improved Estimation in Linear Models. John Wiley \& Sons, London, UK.

Boeckaert, C., B. Vlaeminck, J. Dijkstra, A. Issa-Zacharia, T. Van Nespen, W. Van Straalen, and V. Fievez. 2008. Effect of dietary starch or micro algae supplementation on rumen fermentation and milk fatty acid composition of dairy cows. J. Dairy Sci. 91:47144727. https://doi.org/10.3168/jds.2008-1178.

Cabrita, A. R. J., A. J. M. Fonseca, R. J. Dewhurst, and E. Gomes. 2003. Nitrogen supplementation of corn silages. 2. Assessing rumen function using fatty acid profiles of bovine milk. J. Dairy Sci 86:4020-4032. https://doi.org/10.3168/jds.S0022-0302(03)74013 $-2$.

Carreño, D., G. Hervás, P. G. Toral, T. Castro-Carrera, and P. Frutos. 2016. Fish oil-induced milk fat depression and associated downregulation of mammary lipogenic genes in dairy ewes. J. Dairy Sci. 99:7971-7981. https://doi.org/10.3168/jds.2016-11019.

Castro-Montoya, J., A. Henke, J. Molkentin, K. Knappstein, A. Susenbeth, and U. Dickhoefer. 2016. Relationship between milk odd and branched-chain fatty acids and urinary purine derivatives in dairy cows supplemented with quebracho tannins - A study to test milk fatty acids as predictors of rumen microbial protein synthesis. Anim. Feed Sci. Technol. 214:22-33. https://doi.org/10.1016/ j.anifeedsci.2016.01.016.

Collomb, M., H. Sollberger, U. Bütikofer, R. Sieber, W. Stoll, and W. Schaeren. 2004. Impact of a basal diet of hay and fodder beet supplemented with rapeseed, linseed and sunflowerseed on the fatty acid composition of milk fat. Int. Dairy J. 14:549-559. https://doi .org/10.1016/j.idairyj.2003.11.004.

Draper, N. R., and H. Smith. 1998. Applied Regression Analysis. John Wiley \& Sons Inc., New York, NY.

Emmanuel, B. 1978. The relative contribution of propionate, and longchain even-numbered fatty acids to the production of long-chain 
odd-numbered fatty acids in rumen bacteria. Biochim. Biophys. Acta 528:239-246. https://doi.org/10.1016/0005-2760(78)90198-4.

Enjalbert, F., S. Combes, A. Zened, and A. Meynadier. 2017. Rumen microbiota and dietary fat: a mutual shaping. J. Appl. Microbiol. 123:782-797. https://doi.org/10.1111/jam.13501.

Fievez, V., E. Colman, J. M. Castro-Montoya, I. Stefanov, and B. Vlaeminck. 2012. Milk odd- and branched-chain fatty acids as biomarkers of rumen function - An update. Anim. Feed Sci. Technol. 172:51-65. https://doi.org/10.1016/j.anifeedsci.2011.12.008.

Fougère, H., C. Delavaud, and L. Bernard. 2018. Diets supplemented with starch and corn oil, marine algae, or hydrogenated palm oil differentially modulate milk fat secretion and composition in cows and goats: A comparative study. J. Dairy Sci. 101:8429-8445. https://doi.org/10.3168/jds.2018-14483.

Frutos, P., P. G. Toral, and G. Hervás. 2017. Individual variation of the extent of milk fat depression in dairy ewes fed fish oil: Milk fatty acid profile and mRNA abundance of candidate genes involved in mammary lipogenesis. J. Dairy Sci. 100:9611-9622. https://doi .org/10.3168/jds.2017-13354.

Gómez-Cortés, P., M. A. de la Fuente, P. G. Toral, P. Frutos, M. Juárez, and G. Hervás. 2011. Effects of different forage:concentrate ratios in dairy ewe diets supplemented with sunflower oil on animal performance and milk fatty acid profile. J. Dairy Sci. 94:45784588. https://doi.org/10.3168/jds.2010-3803.

Gómez-Cortés, P., P. Frutos, A. R. Mantecón, M. Juárez, M. A. de la Fuente, and G. Hervás. 2008. Milk production, conjugated linoleic acid content, and in vitro ruminal fermentation in response to high levels of soybean oil in dairy ewe diet. J. Dairy Sci. 91:1560-1569. https://doi.org/10.3168/jds.2007-0722.

Hervás, G., P. Luna, A. R. Mantecón, N. Castañares, M. A. de la Fuente, M. Juárez, and P. Frutos. 2008. Effect of diet supplementation with sunflower oil on milk production, fatty acid profile and ruminal fermentation in lactating dairy ewes. J. Dairy Res. 75:399-405. https://doi.org/10.1017/S0022029908003506.

INRA. 2007. Alimentation des bovins, ovins et caprins. Besoins des Animaux: Valeur des aliments. Tables INRA 2007. INRA, Versailles, France.

Jing, L., L. Dewanckele, B. Vlaeminck, W. M. Van Straalen, A. Koopmans, and V. Fievez. 2018. Susceptibility of dairy cows to subacute ruminal acidosis is reflected in milk fatty acid proportions, with $\mathrm{C} 18: 1$ trans-10 as primary and $\mathrm{C} 15: 0$ and $\mathrm{C} 18: 1$ trans-11 as secondary indicators. J. Dairy Sci. 101:9827-9840. https://doi .org/10.3168/jds.2018-14903.

Kaneda, T. 1991. Iso- and anteiso-fatty acids in bacteria: Biosynthesis, function, and taxonomic significance. Microbiol. Rev. 55:288-302. https://doi.org/10.1128/MMBR.55.2.288-302.1991.

Leduc, M., M. P. Létourneau-Montminy, R. Gervais, and P. Y. Chouinard. 2017. Effect of dietary flax seed and oil on milk yield, gross composition, and fatty acid profile in dairy cows: A meta-analysis and meta-regression. J. Dairy Sci. 100:8906-8927. https://doi.org/ $10.3168 /$ jds.2017-12637.

Lee, H. J., J. Y. Jung, Y. K. Oh, S. S. Lee, E. L. Madsen, and C. O. Jeon. 2012. Comparative survey of rumen microbial communities and metabolites across one caprine and three bovine groups, using bar-coded pyrosequencing and $\mathrm{H}-1$ nuclear magnetic resonance spectroscopy. Appl. Environ. Microbiol. 78:5983-5993. https://doi .org/10.1128/AEM.00104-12.

Lourenço, M., E. Ramos-Morales, and R. J. Wallace. 2010. The role of microbes in rumen lipolysis and biohydrogenation and their manipulation. Animal 4:1008-1023. https://doi.org/10.1017/ S175173111000042X

Maia, M. R., L. C. Chaudhary, L. Figueres, and R. J. Wallace. 2007. Metabolism of polyunsaturated fatty acids and their toxicity to the microflora of the rumen. Antonie Van Leeuwenhoek 91:303-314. https://doi.org/10.1007/s10482-006-9118-2.

Mele, M., A. Serra, A. Buccioni, G. Conte, A. Pollicardo, and P. Secchiari. 2008. Effect of soybean oil supplementation on milk fatty acid composition from Saanen goats fed diets with different forage: concentrate ratios. Ital. J. Anim. Sci. 7:297-311. https://doi.org/ 10.4081/ijas.2008.297.
Mitchell, P. L. 1997. Misuse of regression for empirical validation of models. Agric. Syst. 54:313-326. https://doi.org/10.1016/S0308 $-521 X(96) 00077-7$.

Moon, Y. H., J. U. Ok, S. J. Lee, J. K. Ha, and S. S. Lee. 2010. A comparative study on the rumen microbial populations, hydrolytic enzyme activities and dry matter degradability between different species of ruminant. Anim. Sci. J. 81:642-647. https://doi.org/10 $.1111 /$ j.1740-0929.2010.00782.x.

Palmer, E., M. Baldin, D. E. Rico, and K. J. Harvatine. 2016. Changes in milk odd and branched-chain fatty acids during induction and recovery from biohydrogenation-induced milk fat depression. J. Dairy Sci. 99(E-Suppl. 1):643. (Abstr.)

Patel, M., E. Wredle, and J. Bertilsson. 2013. Effect of dietary proportion of grass silage on milk fat with emphasis on odd- and branched-chain fatty acids in dairy cows. J. Dairy Sci. 96:390-397. https://doi.org/10.3168/jds.2012-5441.

Prado, L. A., P. Schmidely, P. Nozière, and A. Ferlay. 2019. Milk saturated fatty acids, odd- and branched-chain fatty acids, and isomers of $\mathrm{C} 18: 1, \mathrm{C} 18: 2$, and $\mathrm{C} 18: 3 \mathrm{n}-3$ according to their duodenal flows in dairy cows: A meta-analysis approach. J. Dairy Sci. 102:3053-3070. https://doi.org/10.3168/jds.2018-15194.

Ran-Ressler, R. R., S. Bae, P. Lawrence, D. H. Wang, and J. T. Brenna. 2014. Branched-chain fatty acid content of foods and estimated intake in the USA. Br. J. Nutr. 112:565-572. https://doi.org/10 $.1017 /$ S0007114514001081.

Rego, O. A., H. J. D. Rosa, P. V. Portugal, T. Franco, C. M. Vouzela, A. E. S. Borba, and R. J. B. Bessa. 2005. The effects of supplementation with sunflower and soybean oils on the fatty acid profile of milk fat from grazing dairy cows. Anim. Res. 54:17-24. https:/ /doi.org/10.1051/animres:2005002.

Saliba, L., R. Gervais, Y. Lebeuf, and P. Y. Chouinard. 2014. Effect of feeding linseed oil in diets differing in forage to concentrate ratio: 1. Production performance and milk fat content of biohydrogenation intermediates of $\alpha$-linolenic acid. J. Dairy Res. 81:82-90. https://doi.org/10.1017/S0022029913000691.

Sauvant, D., P. Schmidely, J. J. Daudin, and N. R. St-Pierre. 2008. Meta-analyses of experimental data in animal nutrition. Animal 2:1203-1214. https://doi.org/10.1017/S1751731108002280.

Shingfield, K. J., S. Ahvenjärvi, V. Toivonen, A. Äröla, K. V. V. Nurmela, P. Huhtanen, and J. M. Griinari. 2003. Effect of dietary fish oil on biohydrogenation of fatty acids and milk fatty acid content in cows. Anim. Sci. 77:165-179. https://doi.org/10.1017/ S1357729800053765.

Shingfield, K. J., Y. Chilliard, V. Toivonen, P. Kairenius, and D. I. Givens. 2008. Trans fatty acids and bioactive lipids in ruminant milk. Adv. Exp. Med. Biol. 606:3-65. https://doi.org/10.1007/978 -0-387-74087-4_1.

St-Pierre, N. R. 2001. Invited review: Integrating quantitative findings from multiple studies using mixed model methodology. J. Dairy Sci. 84:741-755. https://doi.org/10.3168/jds.S0022-0302(01)74530 -4 .

St-Pierre, N. R. 2003. Reassessment of biases in predicted nitrogen flows to the duodenum by NRC 2001. J. Dairy Sci. 86:344-350. https://doi.org/10.3168/jds.S0022-0302(03)73612-1.

Toral, P. G., R. Gervais, G. Hervás, M. P. Létourneau-Montminy, and P. Frutos. 2020. Relationships between trans-10 shift indicators and milk fat traits in dairy ewes: Insights into milk fat depression. Anim. Feed Sci. Technol. 261:114389. https://doi.org/10.1016/j .anifeedsci.2020.114389.

Toral, P. G., G. Hervás, D. Carreño, and P. Frutos. 2016. Does supplemental 18:0 alleviate fish oil-induced milk fat depression in dairy ewes? J. Dairy Sci. 99:1133-1144. https://doi.org/10.3168/jds 2015-10304

Toral, P. G., G. Hervás, H. Leskinen, K. J. Shingfield, and P. Frutos. 2018. In vitro ruminal biohydrogenation of eicosapentaenoic (EPA), docosapentaenoic (DPA), and docosahexaenoic acid (DHA) in cows and ewes: Intermediate metabolites and pathways. J. Dairy Sci. 101:6109-6121. https://doi.org/10.3168/jds.2017 $-14183$. 
Vazirigohar, M., M. Dehghan-Banadaky, K. Rezayazdi, A. Nejati-Javaremi, H. Mirzaei-Alamouti, and A. K. Patra. 2018. Short communication: Effects of diets containing supplemental fats on ruminal fermentation and milk odd- and branched-chain fatty acids in dairy cows. J. Dairy Sci. 101:6133-6141. https://doi.org/10.3168/ jds.2017-14189.

Ventto, L., H. Leskinen, P. Kairenius, T. Stefanski, A. R. Bayat, J. Vilkki, and K. J. Shingfield. 2017. Diet-induced milk fat depression is associated with alterations in ruminal biohydrogenation pathways and formation of novel fatty acid intermediates in lactating cows. Br. J. Nutr. 117:364-376. https://doi.org/10.1017/ S0007114517000010.

Vlaeminck, B., V. Fievez, A. R. J. Cabrita, A. J. M. Fonseca, and R. J. Dewhurst. 2006. Factors affecting odd- and branched-chain fatty acids in milk: A review. Anim. Feed Sci. Technol. 131:389-417. https://doi.org/10.1016/j.anifeedsci.2006.06.017.

Vlaeminck, B., R. Gervais, M. M. Rahman, F. Gadeyne, M. Gorniak, M. Doreau, and V. Fievez. 2015. Postruminal synthesis modifies the odd- and branched-chain fatty acid profile from the duodenum to milk. J. Dairy Sci. 98:4829-4840. https://doi.org/10.3168/jds .2014-9207.

Weisbjerg, M. R., C. F. Børsting, and T. Hvelplund. 1992. The influence of tallow on rumen metabolism, microbial biomass synthesis and fatty acid composition of bacteria and protozoa. Acta Agric. Scand. Anim. Sci. 42:138-147. https://doi.org/10.1080/ 09064709209410121.

\section{ORCIDS}

P. G. Toral ๑ https://orcid.org/0000-0002-1913-7707

G. Hervás ๑ https://orcid.org/0000-0002-0013-7459

A. Della Badia @ https://orcid.org/0000-0002-2685-5328

R. Gervais (ㄴ) https://orcid.org/0000-0002-6929-2027

P. Frutos () https://orcid.org/0000-0002-4919-5094 